\title{
Octavio Gouvêa de Bulhões
}

\author{
FAUSTO SARETTA
}

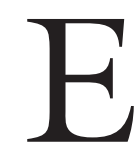

STUDAR As idéias econômicas de Octavio Gouveia de Bulhões equivale, de alguma maneira, a estudar a própria economia brasileira no período que, grosso modo, vai do início da década de 30 até o final dos anos 80 . A longa carreira de Bulhões no setor público iniciou-se em 1926 quando, ainda bastante jovem (22 anos), ingressou na Diretoria do Imposto de Renda. Ao longo dos anos seguintes, e até sua morte em outubro de 1990, em maior ou menor escala, atuou na vida pública, seja como alto funcionário do Estado, seja como participante ativo do debate econômico brasileiro (1).

Bulhões fez parte de um seleto grupo de economistas que deu início aos modernos estudos da economia brasileira. Bacharel em Direito, jamais exerceu a profissão de advogado. Foi atraído para os estudos de Economia pelo contato precoce com o livro de Adam Smith, A riqueza das nações, que o influenciaria ao longo de sua carreira. Devido a isso, ainda integrou aquele grupo de economistas - não formalmente graduados em Economia - uma carreira inexistente no currículo universitário brasileiro da década de 20 , mas que se interessaram pelo estudo da Economia, com vistas a entender e transformar a economia brasileira.

Seu autodidatismo, como o de outros - notadamente Eugênio Gudin contribuiu para sua participação na proposta de criar a Faculdade Nacional de Ciências Econômicas na então Universidade do Brasil. Boa parte da trajetória de Bulhões como servidor público esteve marcada pelo pionerismo, visto que a par da criação de importantes órgãos públicos para a melhoria da administração, e mesmo da compreensão, dos problemas econômicos nacionais, fez-se notar na defesa de suas idéias por meio da publicação de livros e de numerosos artigos.

Na década de 30, a convite de Luiz Simões Lopes (presidente do DASP), foi aos Estados Unidos para um estágio na American University, onde estabeleceu contatos com importantes professores norte-americanos de Economia. Esta vivência associada às leituras que fez, principalmente da obra do economista sueco Knut Wicksell, Lectures on political economy, marcaria boa parte de suas idéias sobre Economia e de seus escritos mais importantes (2). Registre-se que a exemplo do já citado Eugênio Gudin, também Bulhões buscou trazer para o debate brasileiro o ideário de importantes economistas de outros países, com o intuito de melhor compreender a nossa economia e os seus principais problemas.

Este caráter aqui chamado de pioneiro revela-se na sua trajetória profissional, toda ela como funcionário do Ministério da Fazenda, onde se notabilizou 
pela criação de aparelhos regulatórios na área monetária, com destaque para a Superintendência da Moeda e do Crédito (SUMOC), que serviria de base para a posterior criação do Banco Central do Brasil.

Pode-se afirmar inclusive que na criação destes dois órgãos foi de fundamental importância o empenho pessoal de Octavio Bulhões, o que expressa em boa medida o núcleo central de suas preocupações e interesses. Seja como professor universitário de Economia, seja como ministro da Fazenda (entre outros cargos e funções desempenhados no serviço público), a longa lista de trabalhos publicados por Bulhões tem como eixo central a preocupação com as questões monetárias e, por isto mesmo, com o problema recorrente que foi durante bom tempo a inflação brasileira. A despeito dos riscos contidos nas generalizações, pode-se afirmar que a preocupação central contida na obra de Bulhões está relacionada à moeda, e o aspecto que ganha destaque nela é a sua persistência no combate à inflação.

Esta breve caracterização possibilita desde já classificá-lo, dentro do quadro geral do pensamento econômico brasileiro, como neoliberal. Mas, em toda classificação há sempre a possibilidade de um reducionismo empobrecedor. Mesmo assim, a filiação teórica de Bulhões sempre esteve claramente associada ao grupo de economistas que teve em Eugênio Gudin o mais notável e destacado de seus pensadores, sem dúvida o líder intelectual desta corrente.

A despeito dos diferentes matizes existentes entre os economistas que compunham esta corrente de pensamento, há um ponto forte que os liga. Assim, se Gudin perfila entre os que defendiam a vocação agrícola da economia brasileira e eram contrários a qualquer medida industrializante, Bulhões já não era tão contrário ao avanço industrial, embora não advogasse medidas de suporte direto a este setor, e defendesse principalmente a estabilidade monetária. A essa defesa da estabilidade monetária estava associado um papel específico para a intervenção estatal, enquanto que ao capital estrangeiro caberia uma função decisiva e fundamental no desenvolvimento econômico (3).

O que unia esses economistas, e dava maior substrato a seus pensamento e ação foi a ênfase nas questões monetárias, vale dizer, na estabilidade da economia. Como bem aponta Bielchowsky, o projeto econômico básico desta corrente era o crescimento equilibrado em que o sistema de preços relativos teria a função essencial de nortear os investimentos. Baseada em primados que se poderia chamar de liberais, considerava que os desequilíbrios da economia, mais precisamente do processo de seu crescimento, decorriam dos erros da política econômica. Outras características importantes eram o favorecimento ao capital estrangeiro, a restrição à empresa estatal, uma tolerância mínima quanto ao planejamento e algum aceite de protecionismo, sobretudo via tarifas - como, por exemplo, para a chamada indústria infante. 
Este ideário brevemente descrito encontrou maior efetividade nas propostas de política econômica que visavam, antes de tudo, a estabilização, já que a inflação era tida como a principal causa do déficit externo, além de implicar reajustes salariais, quando os salários deveriam ser determinados na boa tradição neoclássica em função da produtividade marginal do fator trabalho (4). Octavio Gouvêa de Bulhões e Eugênio Gudin são considerados os líderes desta corrente. Com efeito, uma observação mesmo que ligeira de sua produção confirma a procedência da classificação como neoliberal, ainda que permaneçam algumas diferenças entre seus principais membros. Além disso, há de se considerar que a longa e importante carreira de Bulhões como servidor público, expressou em boa medida as idéias que defendeu, já que teve a possibilidade em momentos importantes da vida econômica nacional, de agir coerentemente com estes princípios. Nos parágrafos que seguem procurar-se-á traçar um perfil e fazer uma análise de seus trabalhos, bem como de sua importância para a economia brasileira.

\section{Idéias e ação}

"Octavio Bulhões é talvez no Brasil o melhor exemplo de civil servant na melhor acepção do termo, um homem preocupado e pessoalmente envolvido com os problemas nacionais, profundamente honesto no ponto de vista intelectual e na defesa de sua noção do interesse público. Muitas dessas qualidades são comuns ao grupo de economistas que se formam em torno dele e de Eugênio Gudin, talvez em seu tempo o mais preparado e com maior ofício na área monetária, com características não apenas de excelência técnica mas de origem ou situação social favorecidas" (5).

Uma primeira aproximação à obra de Bulhões indicaria que sua preocupação central esteve sempre mais direcionada para os aspectos práticos da Economia, vale dizer, para as questões relacionadas à política econômica, pesando bem menos o trato de aspectos doutrinários. Neste sentido, Bulhões difere de Eugênio Gudin, o mais influente membro do grupo a que esteve permanentemente ligado e que se envolveu na célebre polêmica com o industrial paulista Roberto Simonsen na década de 40. Uma breve observação da vasta obra de Gudin confirmaria que o seu foco esteve sempre permeado da defesa dos postulados das economias clássica e neoclássica, e em permanente polêmica com as visões econômicas divergentes, principalmente quando estas estavam centradas no intervencionismo estatal - planejamento - e em restrições ao capital estrangeiro, afora outras referentes à estabilidade econômica e inflação.

Bielschowsky lembra que Bulhões teria tido uma maior tolerância, ou melhor aceitabilidade quanto ao processo de industrialização, exatamente por sabêlo irreversível. No entanto, se os dois grandes economistas liberais brasileiros bateram-se por uma política econômica semelhante, como por exemplo quanto à 
inflação e ao câmbio, entre outras questões importantes, discordaram quanto à criação do Banco Central - que seria a base para a instituição de um sistema financeiro essencial para o aumento da poupança e do investimento produtivo (6).

Vale lembrar que em dois momentos importantes da vida econômica brasileira Bulhões agiu a favor da criação do Banco Central. Em 1945, criou a Superintendência da Moeda e do Crédito (SUMOC) que, embora não tivesse exatamente o mesmo papel de um banco central, desempenhou uma função importante na administração pública nacional. Mais tarde, em 1964, a SUMOC se revelaria a base para a criação do Banco Central, também por inspiração de Bulhões.

Ao contrário da opinião de Gudin, que julgava imprópria a criação de um órgão regulador da moeda e do crédito dentro de uma conjuntura inflacionária, Octavio Bulhões viabilizou o surgimento da SUMOC no final do primeiro governo Vargas, com a inflação ascendente. Mesmo à sombra da principal instituição de crédito e autoridade monetária de então, o Banco do Brasil, a SUMOC teria um papel importante na administração da política econômica. Nos 20 anos seguintes, a SUMOC deliberaria sobre questões das mais relevantes e teria influência não menos relevante no desenvolvimento da economia brasileira. Apenas de passagem, registre-se a importância da Superintendência quanto ao Decreto Lei n. ${ }^{\circ}$ 9025, de fevereiro de 1946, que fixava os percentuais relativos à remessa de lucros para os capitais estrangeiros, a célebre Instrução 113 de janeiro de 1955, e a de número 204 quando do início do governo Jânio Quadros (7).

A SUMOC, pode-se afirmar, foi uma criação de Bulhões. Importa considerar também que, em torno deste importante órgão governamental, congregou-se um não menos importante grupo de economistas, o qual, a exemplo de seu fundador, devotou-se ao estudo dos problemas monetários e fiscais e à necessidade de se ter controles mais efetivos sobre a moeda e o crédito. O debate econômico brasileiro foi bastante influenciado por este grupo, que imprecisamente poderia ser denominado monetarista, principalmente por propugnar o controle da inflação. Neste sentido, haveria uma ligação da Superintendência com a Faculdade de Economia e, posteriormente, com a Fundação Getúlio Vargas, o IBRE (Instituto Brasileiro de Economia) e a publicação da Revista Brasileira de Economia, fundada em 1947 (8).

Considera-se que as preocupações de Bulhões com o controle monetário ter-se-iam tornado mais definitivas após a sua participação, junto com Gudin, Roberto Campos e outros, no encontro de Bretton Woods, que fundou o FMI e o Banco Mundial. Além disso, as propostas quanto a regimes cambiais, comércio exterior, capital estrangeiro, papel do Estado, tarifas etc., oriundas do encontro, teriam marcado as concepções de Bulhões e transformado o grupo da SUMOC no principal interlocutor do FMI junto às autoridades brasileiras (9). 
Como já observado, Bulhões teve uma longa e importante carreira no setor público. Também se anotou sua importância na criação de órgãos públicos ou não, devotados tanto à administração quanto à pesquisa e ao estudo da Economia. Pode-se afirmar que há uma notável consistência nos inúmeros textos que publicou, relacionados à sua atuação seja como diretor da SUMOC, seja como ministro da Fazenda, este sendo evidentemente o cargo que lhe deu maior visibilidade no cenário econômico brasileiro. Há de se considerar que sua atuação nos importantes cargos que teve obrigou-o a submeter-se às diretrizes de ordem política, ainda mais considerando o acidentado percurso da vida econômica e política brasileira no período posterior a 1930.

Entretanto, a despeito de seu liberalismo encontrar mais coerência nos seus escritos do que na sua atuação propriamente dita, nota-se em ambas as instâncias a defesa de seus pontos de vista, de suas concepções em relação à economia nacional. Sua biografia de civil servant inicialmente registra seu empenho na concepção do controvertido Decreto-Lei n. ${ }^{\circ} 9025$, de fevereiro de 1946, que estabelecia a liberdade de compra e venda de cambiais e regulamentava as remessas do capital estrangeiro investido no país. Cumpre lembrar brevemente que as disposições deste Decreto-Lei eram por demais restritivas para a atração dos capitais estrangeiros e que, decorridos apenas seis meses de sua promulgação, foram feitas modificações que buscavam flexibilizar e tornar mais atrativa a vinda dos tão esperados capitais. A conjuntura internacional daqueles anos do imediato pós Segunda Guerra não era muito propícia à entrada de capitais estrangeiros, e assim de pouco valeram as alterações efetivadas.

Outra participação importante de Bulhões naqueles anos da segunda metade da década de 40 diz respeito ao valor da taxa de câmbio para o Fundo Monetário Internacional, o que era essencial para que o país pudesse dispor dos recursos do Fundo. A fixação da taxa em Cr\$ 18,50 por dólar norte-americano, o mesmo valor do pré-Guerra, portanto valorizado, decorreu das dificuldades cambiais vividas pela economia nacional naqueles anos e, de alguma maneira, expressava o relativo quadro de descoordenação da política econômica sob a administração Dutra (10).

Ainda na segunda metade dos anos 40, Bulhões participou como representante brasileiro da Missão Abbink - como ficou conhecida a Comissão Mista Brasileiro-Americana de Estudos Econômicos chefiada pelo norte-americano John Abbink. A participação de Bulhões ensejou a publicação do livro $\grave{A}$ margem de um Relatório. Convém recordar que a Missão na verdade foi mais um fator do crescente descontentamento que tomava conta das autoridades e dos empresários brasileiros, frustrados com a relativa indiferença do governo dos EUA com a economia brasileira. As conclusões do Relatório, pregando políticas econômicas de estabilização e incentivos à vinda de capitais privados estrangeiros, em nada resolveram a 
aguda escassez de dólares vivenciada pela economia brasileira. Entretanto, o texto de $\grave{A}$ margem serviu como referencial para a discussão da política econômica e do próprio desenvolvimento econômico pelo menos até meados da década de 50 (11).

De 1950 até 1954, Bulhões fez parte do Conselho Nacional de Economia, órgão consultivo da Presidência da República. Embora sem um cargo executivo e lecionando na Faculdade Nacional de Economia, participou ativamente do debate econômico brasileiro da época. Para alguns estudiosos de sua obra, o início da década de 50 marcaria uma inflexão no pensamento de Bulhões, e isto se fez quando começaram ganhar corpo na discussão brasileira sobre o desenvolvimento econômico as idéias oriundas da CEPAL.

Aquela década foi sabidamente um período em que o confronto das diferentes concepções sobre o candente tema do desenvolvimento econômico brasileiro revelou toda a sua intensidade. O debate da década anterior entre Roberto Simonsen e Eugenio Gudin ganhara um reforço importante com o intervencionismo estatal e com o planejamento econômico cepalino, que assim estariam legitimando teoricamente os argumentos outrora defendidos por Simonsen. Em meio à política de cores nacionalistas do segundo governo Vargas, Octavio Bulhões ter-se-ia convertido definitivamente ao ideário liberal (12).

Antes de tratar adequadamente de seus escritos e idéias, é preciso lembrar ainda que, após a grave crise política que culminou no suicídio de Vargas, o novo presidente Café Filho nomeou Gudin para o Ministério da Fazenda, Clemente Mariani para a presidência do Banco do Brasil e Octavio Bulhões para a diretoria da SUMOC. A nova equipe assumiu dentro de um quadro econômico em que se conjugavam uma inflação crescente e um pesado desequilíbrio externo. A breve gestão de Gudin à frente do Ministério da Fazenda significou um forte programa ortodoxo de combate à inflação, o que teria desagradado sobretudo aos interesses do empresariado paulista, que conseguiu afastá-lo do Ministério decorridos pouco mais de oito meses. Aqui deve ser mencionada uma das mais importantes medidas tomadas no período: a Instrução 113, de 27 de janeiro de 1955, que permitia ao Banco do Brasil emitir licenças de importação sem cobertura cambial para equipamentos que "complementassem os conjuntos já existentes no país e estivessem classificados nas três primeiras categorias de importação".

A historiografia econômica brasileira é unânime em reconhecer o favorecimento que a Instrução 113 significou para o capital estrangeiro. Além disso, em função das dificuldades do mercado internacional de crédito em financiar o desequilíbrio externo brasileiro, optou-se por uma estratégia de enfrentamento de longo prazo, tal como a proposta pela Instrução. Mas, é importante lembrar que boa parte do sucesso do avanço industrial do governo Juscelino Kubitschek deveu-se à Instrução 113 (13). A respeito dela, Octavio Bulhões deixou clara a 
importância que tal regulamentação teve para a indústria, notadamente a automobilística, e aproveitou para desautorizar aqueles que consideravam Eugênio Gudin, o verdadeiro mentor da Instrução, como contrário ao desenvolvimento industrial (14).

Nos anos da segunda metade da década de 50, Bulhões continuou no Conselho Nacional de Economia e foi um crítico severo da administração JK. Entretanto, suas críticas mais contundentes não foram quanto ao avanço da industrialização, que reconhecia como válida, mas quanto à construção de Brasília, por ser fiel às suas principais preocupações e temer o avanço da inflação. Nas sua próprias palavras: "Queriam vencer a economia, como dizia o próprio presidente, fazendo em cinco anos o que poderia ser feito em 50. Mas 50 em cinco acaba dando 500 em matéria inflacionária” (15).

Bulhões voltou à SUMOC como diretor executivo quando Jânio Quadros assumiu a presidência em janeiro de 1961. Era inegável o quadro de pesados desequilíbrios macroeconômicos legado do período anterior, principalmente pela iminência de um colapso cambial. Esta dificuldade levou à Instrução 204, de 13 de março daquele ano, reformando o regime cambial que, grosso modo, vigorava desde 1953, época da Instrução 70 (16).

A Instrução 204 visava criar um clima favorável para a negociação dos pesados desequilíbrios das contas externas e reforçar o combate ao déficit público. Sua implantação significou um aumento nos índices inflacionários até porque as importações consideradas essenciais - trigo, petróleo e papel de imprensa - tiveram sua taxa de câmbio desvalorizada em 100\%. Outras questões importantes entrariam numa análise mais cuidadosa da Instrução propriamente dita e de seus efeitos sobre a economia nacional. A brevidade do mandato de Quadros não permite entretanto maiores conclusões a respeito.

Em meio à crise política que se seguiu, Bulhões continuaria à frente da SUMOC até o final de 1962. As razões para sua saída seriam principalmente a aprovação da lei de remessa de lucros - a Lei n. ${ }^{\circ} 4131$ - que fora elaborada pelo próprio Bulhões e por Clemente Mariani, ainda no governo de Quadros e aprovada em 3 de setembro de 1962, baseada em um substitutivo de Celso Brant (17).

Octavio Gouvêa de Bulhões atingiria o ápice de sua longa carreira de servidor público como ministro da Fazenda do governo Castelo Branco entre 1964 e 1967. O combate aos desequilíbrios econômicos expressos, sobretudo na inflação prevista para 1964 (da ordem de 100\%) e na baixa taxa de crescimento da economia no ano anterior $(0,6 \%)$, levaram o ministro, juntamente com Roberto Campos, na condição de ministro do Planejamento e Coordenação Econômica, a formularem o Plano de Ação Econômica do Governo (PAEG) (18). 
Em linhas gerais, o novo programa propunha manter o ritmo de crescimento que sofrera marcante redução nos dois anos anteriores, combater a inflação, atenuar os desníveis regionais e setoriais, aumentar os investimentos e conseqüentemente as oportunidades de emprego, e corrigir os desequilíbrios das contas externas. Para além das medidas de política econômica, e não menos importantes, foram efetivadas reformas de natureza estrutural como a bancária e a tributária. Criaram-se finalmente o Banco Central e o Conselho Monetário Nacional e regulamentou-se o mercado de capitais. Da maior importância também foi a criação do Banco Nacional da Habitação que, amparado no também novo FGTS, financiaria o setor da construção civil. Além disso, destaque-se a criação dos títulos públicos denominados de Obrigações Reajustáveis do Tesouro Nacional e a cláusula da correção monetária com o objetivo de recomposição das receitas públicas.

Certamente uma análise da economia e da política econômica nos anos imediatos após o movimento militar de março de 1964 teria um escopo bem mais amplo do que o que pode ser proposto neste texto. Convém lembrar, entretanto, que o PAEG e as reformas do período em que Bulhões foi ministro da Fazenda serviram de base para o notável surto de crescimento que ocorreu de 1968 até 1973 - o chamado período do "milagre brasileiro". Não menos importante é lembrar que a política econômica da administração Castelo Branco demonstrou os limites que se permitem para políticas que na falta de melhor expressão se denominaria de ortodoxas. Mesmo no contexto político inegavelmente autoritário daqueles anos, quando supostamente se poderia ter limites elásticos para impor a estabilização, optou-se por uma linha mais gradualista, de maior acomodação face aos interesses efetivos existentes na economia nacional. Em outras palavras, $\mathrm{o}$ sucesso da política de combate à inflação naquele contexto autoritário esteve muito mais associado às mudanças na política salarial do que propriamente à recessão $\mathrm{e}$ ao desemprego (19).

\section{Contribuição ao pensamento econômico}

Buscou-se nas linhas acima traçar um sumário da longa e importante carreira de Octavio Gouvêa de Bulhões na administração pública brasileira, principalmente nos seus momentos mais significativos, que não foram poucos. Convém agora tratar de sua contribuição ao debate econômico brasileiro, contribuição que ele deu através de um conjunto substancioso de livros e artigos, centrados, como já se observou, menos em questões doutrinárias, e mais naquilo que se poderia denominar de Economia Aplicada, mais precisamente nas questões atinentes à Política Econômica. Mário Henrique Simonsen, escrevendo em homenagem a Bulhões observou exatamente esta faceta de sua obra: "compreendia a teoria econômica como um conjunto de princípios a serviço da política econômica, e não como um conjunto de explorações intelectuais desenvolvidas por acadêmicos para ser discutido por outros acadêmicos” (20). 
Desta maneira há que selecionar na vasta obra do professor Bulhões, na quase centena de trabalhos que apresentou como livros, artigos e conferências, individualmente ou em co-autoria, o que melhor exprime seu pensamento econômico. O sentido prático ou aplicado de seus trabalhos tratou de uma maneira geral do desenvolvimento brasileiro e do aumento da produtividade. A despeito da dificuldade de fazer uma súmula de tantos trabalhos, é possível destacar desde logo que Bulhões entendia o desenvolvimento econômico como resultado das ações da livre iniciativa, dentro de um regime de produção descentralizado, orientado pelo sistema de preços relativos com intervencionismo estatal mínimo, auxílio do capital estrangeiro e principalmente, com baixa inflação (21).

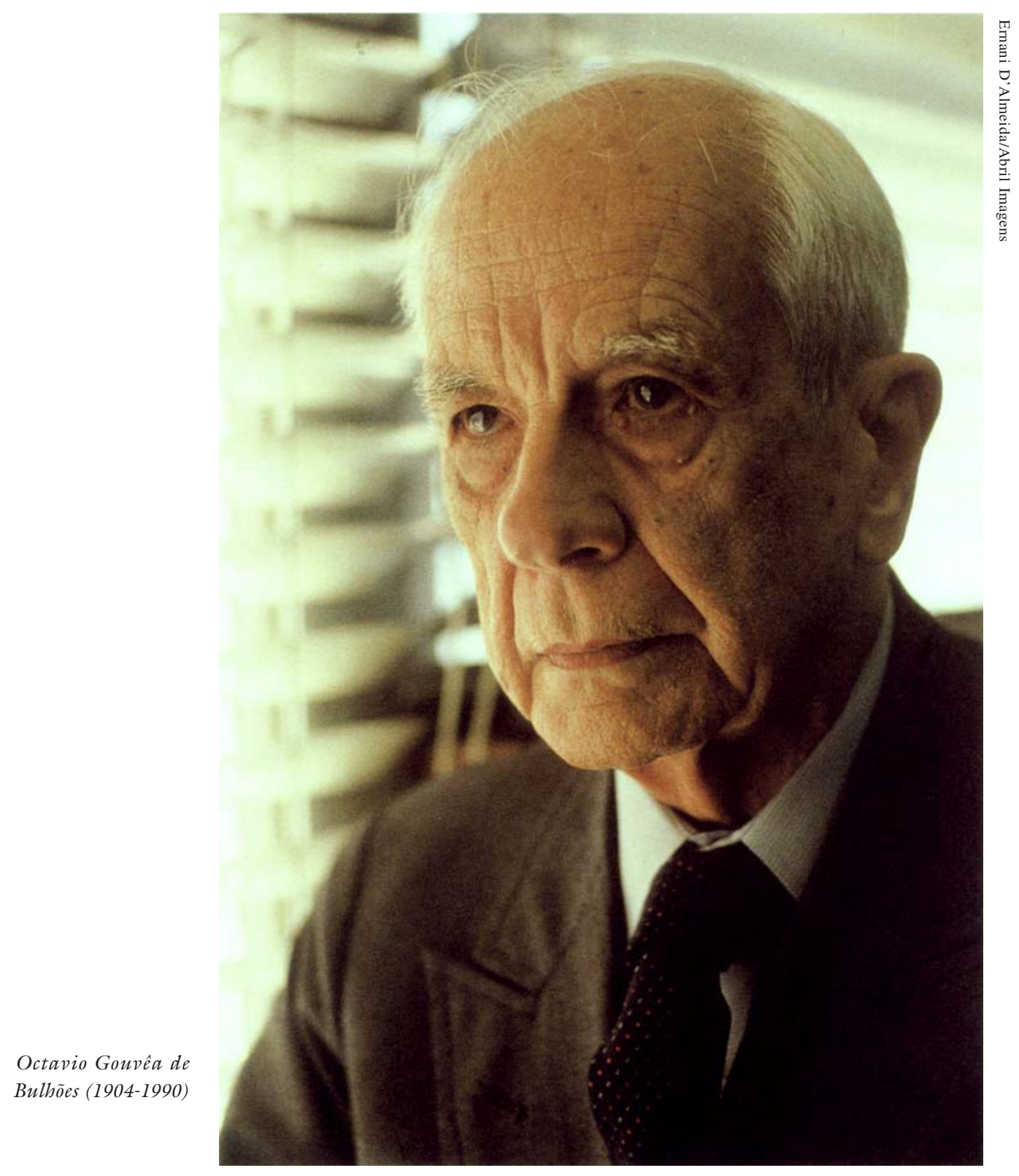


Os mesmos princípios reaparecem em outros trabalhos de Bulhões. Mas, expostos assim de forma algo genérica, poderiam sugerir um tratamento de maneira um tanto quanto simplista de questões econômicas tão importantes. Uma observação mais acurada da já citada vasta bibliografia de Octavio Bulhões permite entender que seu trabalho como economista, nos vários campos em que atuou, teve como elemento comum tanto a coerência quanto a qualidade. Uma apreciação mais qualitativa de seus trabalhos evita desde logo a banalização de suas idéias econômicas, e a sua mera classificação como neoliberal.

O conjunto da obra publicada ao longo de mais de 50 anos aponta para uma tentativa sistemática de incorporação das idéias econômicas tanto do já citado Wicksell, quanto de Keynes, Hicks, Marshall, entre outros, numa tentativa permanente de utilizar os principais autores da literatura econômica internacional para entender a economia brasileira e as formas de desenvolvê-la. O livro Economia e Política Econômica, publicado em 1960, apresenta na sua primeira parte uma contribuição que se poderia denominar teórica, e que mostra o conhecimento e o domínio de Bulhões de importantes obras e autores do pensamento econômico. A segunda parte, denominada "Alguns problemas de opção na economia brasileira”, traça um vasto painel tanto de aspectos históricos quanto dos problemas que então se entendia como atinentes à economia nacional. Uma leitura cuidadosa deste trabalho possibilita entender melhor a atuação de Bulhões para além de um policy maker, demonstrando tanto sua erudição como economista quanto seu papel não menos importante de professor universitário (22).

Na verdade, não é tarefa simples tratar de tão vasta produção em um artigo. Convém, entretanto, considerar que os aspectos centrais que possibilitam, tanto quanto possível, o entendimento da obra de Bulhões, devem ser associados à sua atuação como importante servidor público. Mais do que isso, é possível entender seu pensamento como uma combinação de idéias suficientemente bem embasadas, adaptáveis ao mutante quadro da economia brasileira, com uma dose necessária de pragmatismo, para o encaminhamento da solução dos problemas econômicos nacionais.

Desta maneira, ao polemizar com Celso Furtado nas páginas da Revista do Conselho Nacional de Economia em 1953, fez um esforço para apontar os equívocos que estariam por trás das propostas de planejamento da CEPAL, que desconsiderariam Schumpeter e "o ânimo de progresso entre os produtores nacionais". Criticava a CEPAL por não propor uma aceleração equilibrada - como grifa Bulhões adicionando que o Brasil não era uma economia tendendo à estagnação, prescindindo portanto do planejamento e das interferências no mercado propostas pela CEPAL (23).

Outro trabalho de Octavio Bulhões que merece um destaque especial é o já citado À margem de um Relatório, fruto de sua participação na Missão Abbink. A 
par de constituir um documento de grande valia para entender a situação da economia brasileira na segunda metade da década de 40, pode-se observar a defesa que fazia naquela ocasião da intervenção estatal na economia. Certamente deve ter pesado em parte para esta defesa, o quadro de desalento que vigorava no país nos anos do imediato pós-guerra, o que revela o lado que aqui se chamou de pragmatismo de suas idéias e ações (24).

A citação feita na nota remete a temas que foram recorrentes na obra de Bulhões e, por que não dizer, na sua atuação como homem de Estado: o aumento da produtividade, a diferenciação do caráter físico do meramente monetário, o ganho oriundo antes do aumento dos preços do que aumento do produto. Notese por outro lado a referência à nossa herança ibérica que nos tornara um povo mais afeito ao comércio do que à produção, prejudicando, portanto, a compreensão da permanente necessidade de se aumentar a produtividade física.

Na defesa do desenvolvimento brasileiro destacou sempre a importância do capital estrangeiro, dada a insuficiência da poupança nacional. Devido a isso polemizou com os nacionalistas, contrários ao capital estrangeiro, afirmando que “... nacionalismo é, portanto, meio de ação política com objetivo de preservar a nacionalidade

... defendeu sempre a importância do capital estrangeiro, dada a insuficiência da poupança nacional ... no domínio da língua, da arte, dos costumes, da raça e da economia." E em outro trecho diz que "a melhoria do bem-estar econômico dos indivíduos de um país será tanto mais significativa quanto mais facilmente se puder desenvolver a técnica e a acumulação de capital, mediante a associação de recursos nacionais e estrangeiros" (25).

Procurou-se neste artigo tratar do pensamento de Octavio Gouvêa de Bulhões, de seus trabalhos e da sua importância, nas variadas dimensões que teve para a economia brasileira. Embora aqui não tenha sido tratada sua atuação depois que se afastou do Ministério da Fazenda na segunda metade dos anos 60, é importante destacar que nem por isto deixou de atuar e de se interessar pelos destinos do Brasil e da economia brasileira. Em dezembro de 1988, Octavio Bulhões apresentou ao presidente Sarney uma proposta de combate à inflação baseada no corte drástico das despesas públicas, bloqueio à emissão de moedas e títulos, e conseqüentemente fim da correção monetária e demais instrumentos de indexação. O Plano Verão de janeiro de 1989 teria incorporado algumas de suas sugestões mas, segundo o próprio Bulhões, sofrera alterações inconvenientes, como o aumento de juros e o congelamento de preços" (26). 
Tido por seus contemporâneos como servidor público exemplar e modelo de tolerância e de civilidade no trato profissional e humano, Bulhões marcou positivamente a sociedade e a economia brasileiras. Como bem observou certa vez, "não havendo estabilidade monetária, surgem desentendimentos de diversas naturezas, que prejudicam a marcha do desenvolvimento. Sem dúvida alguma pode haver desenvolvimento sem estabilidade monetária, e talvez até de uma maneira bem acelerada. Mas precisamente porque esse desenvolvimento é acelerado, ele traz distorções, traz desequilíbrios que provocam a recessão e com ela o retrocesso. É preferível progredir mais vagarosamente, com estabilidade monetária, do que rapidamente, sem estabilidade. Essa é a minha filosofia” (27).

Certamente suas idéias continuam bastante atuais.

\section{Notas}

1 Sobre a vida de Bulhões ver Beloch, I. e Abreu, A.A. (coords.). Dicionário históricobiográfico brasileiro 1930-1983, FGV-CPDOC, Rio de Janeiro, Forense-Universitária, 1983.

2 A este respeito veja Bulhões, Octavio G. Depoimento. Memória do Banco Central. Programa de História Oral do FGV-CPDOC. Brasília, Banco Central do Brasil, 1990.

3 Para uma análise das diferentes concepções sobre a economia brasileira veja-se Bresser Pereira, Luiz Carlos. Seis interpretações sobre o Brasil, in Loureiro, Maria Rita (org.). Cinqüenta anos de ciência econômica no Brasil. Petrópolis, FIPE/Vozes, 1997, p. 1769.

4 Esta caracterização baseia-se em Bielschowsky, R., Pensamento econômico brasileiro: 0 ciclo ideológico do desenvolvimentismo, Rio de Janeiro, IPEA-INPES, 1988, p. 284.

5 Cf. Lago, Pedro Aranha Corrêa do. A SUMOC como embrião do Banco Central. Rio de Janeiro, s/d. Dissertação (mestrado). PUC-Departamento de Economia.

6 Bielschowsky, op. cit.

7 Para uma história da SUMOC ver Lago, P., op. cit.

8 Para maiores detalhes destas ligações veja Bielschowsky, op. cit., p. 44 e ss. Mas, vale a pena transcrever um depoimento do próprio Bulhões: "Fui convidado pelo Simões Lopes para participar da Fundação tendo em vista a criação de um instituto de economia. Foi por isso que vim ... Mas, a alma desse projeto foi o dr. Gudin. Ele dava as idéias, acompanhava os trabalhos, e sem ele nada teria acontecido Pretendia criar um instituto, de modo que começou com um núcleo. Foi esse núcleo de economistas que formulou a necessidade de se ter um balanço de pagamento, de se calcular a renda nacional, de se ter um índice de preços, enfim de programar uma série de providências no sentido de se fazer um levantamento mais adequado do que existia até então." Bulhões, O.G., op. cit., p. 66. 
9 Sobre a delegação brasileira em Bretton Woods, veja Campos, Roberto, A lanterna na popa. Rio de Janeiro, Topbooks, 1994, capítulo II, parte 5.

10 Sobre as modificações na legislação brasileira quanto à remessa de lucros e determinação da taxa de câmbio, ver Lago, Pedro Correia, op. cit., p. 33-44. Sobre a política econômica no governo Dutra, ver Malan, Pedro et al., Política econômica externa e industrialização no Brasil: 1939-1952. Rio de Janeiro, IPEA-INPE, 1977.

11 Bulhões, Octavio Gouvêa. À margem de um Relatório. Rio de Janeiro, Edições Financeiras, 1950.

12 Veja a este respeito Reis, Geraldo Antônio dos. O anti-desenvolvimentismo de Bulhões. São Paulo, 1955. Dissertação (mestrado). USP-FFLCH, Departamento de História, especialmente p. 50-83.

13 Sobre o governo Café Filho veja-se Pinho Neto, Demósthenes Madureira de. O interregno Café Filho: 1954-1955, in Abreu, Marcelo de Paiva (org.). A Ordem do Progresso: cem anos de política econômica republicana. Rio de Janeiro, Campus, 1989, p. 151-169.

14 Cf. Bulhões, O.G. Depoimento, p. 110-111.

15 Id., ibid., p. 122.

16 “...a elaboração da Instrução 204 partiu de duas premissas básicas: o novo regime cambial deveria promover a eliminação do desequilíbrio externo, através do binômio unificação-depreciação cambial, e contribuir para o ajuste das contas públicas. A estes fatores juntava-se a necessidade de se promover uma reforma do sistema cambial que fosse bem recebida pelas instituições internacionais com as quais o Brasil teria de renegociar seus compromissos externos, notadamente o FMI e o Eximbank, que eram tradicionalmente hostis, principalmente a primeira, ao sistema de taxas múltiplas." Cf. Mesquita, Mário Magalhães Carvalho. A politica econômica sob Quadros e Goulart. Rio de Janeiro, 1992. Dissertação (mestrado), PUC-Departamento de Economia, p. 68.

17 "Durante esse período (1962) a SUMOC se bateu muito contra a modificação da lei de remessa de lucro. Finalmente a lei foi votada. Pedi então ao presidente que a vetasse. Ele não vetou, mas também não sancionou. Com isso a lei voltou ao Congresso, para ser homologada. E a homologação foi feita à noite, com poucos deputados e senadores. Fui então à televisão e disse que aquilo tinha sido um crime de lesa-pátria. É claro que no dia seguinte fui chamado pelo primeiro-ministro, já na época o Hermes Lima, que aliás era meu amigo. Ele me disse que eu tinha de ser demitido depois do que havia dito." Bulhões, O.G., Depoimento, p. 141.

18 Para uma análise do PAEG veja-se Resende, André Lara. Estabilização e Reforma: 19641967, in Abreu, Marcelo de Paiva (org.), op. cit., p. 213-230.

19 Resende, André Lara, op. cit. Para uma visão mais completa do PAEG e história do período 1964-1967 veja-se Campos, Roberto, op. cit., especialmente o capítulo 12. Para uma boa análise da reforma tributária veja-se Oliveira, Fabrício Augusto de, $A$ 
reforma tributária de 1966 e a acumulação de capital no Brasil, $2^{2}$ ed. Belo Horizonte, Oficina de Livros, 1991.

20 Simonsen, Mário Henrique, apud Reis, Geraldo Antonio, op. cit., p. 16. Este trabalho apresenta uma bibliografia quase completa da obra de Bulhões.

21 "Somente pela adequada formação de preços poderemos assegurar um roteiro econômico num regime descentralizado, o mais indicado para nosso país pela vastidão de seu território e variedade de suas regiões (...) O espírito empresarial é a síntese da ousadia técnica com a segurança financeira, do espírito empreendedor com a disciplina da conduta. A desvalorização da moeda aniquila essa síntese. A queda sistemática do valor da moeda provoca o acúmulo de afoiteza, adicionando ao risco técnico o risco financeiro e retirando do espírito inovador a força da disciplina da conduta. As empresas passam do risco para a aventura. Se conseguem expandir na seqüência de alta dos preços, em breve se interessam mais pelo lucro da valorização dos bens do que pelo aperfeiçoamento da técnica de sua produção; se a elevação dos preços particulares não consegue superar a queda do valor da moeda, caem na estagnação, que é o caso típico das empresas de serviço público." Cf. Bulhões, O.G. Alguns aspectos da ação dos mecanismos de preço. Revista Brasileira de Economia, ano 15, p. 2, jun. 1961.

$22 \mathrm{Na}$ abertura do livro citado, em seção denominada "Algumas considerações preliminares", após agradecer aos economistas com os quais partilha o trabalho no IBRE, lêse: "Beneficiando-me das luzes de tão seleto grupo de economistas, pude consolidar minha convicção de que é possível coordenar e acelerar o ritmo do progresso de uma economia por meio de um adequado sistema tributário, assegurando-se, desse modo, a incontestável vantagem da descentralização da produção. Tais idéias, de coordenação e de aceleração, são associadas à tentativa de conjugação dos exames, parciais e globais, da análise econômica, síntese que venho procurando conseguir nas aulas de 'Valor e formação de Preços', na Faculdade Nacional de Ciências Econômicas. São essas, em resumo, as sugestões que ofereço nas páginas que se seguem". Especificamente sobre Keynes veja-se Bulhões, Octavio Gouvêa. A contribuição de Keynes para a análise das ralações dinâmicas na economia. (Conferência realizada na sessão solene promovida pela Faculdade de Ciências Econômicas, em homenagem à memória de Sir John Maynard Keynes em 2 de maio de 1946.) Rio de Janeiro, Biblioteca do Ministério da Fazenda, 1946.

23 Os textos do debate estão na Revista do Conselho Nacional de Economia, ano II, $\mathrm{n}^{\circ} \mathrm{s}$ 19-20, nov./dez. 1953.

24 “... devemos reconhecer a existência de obstáculos à expansão econômica em nosso país. Justifica-se, por isso, a atuação de nosso governo nalguns empreendimentos que noutros países foram iniciados e desenvolvidos por exclusiva iniciativa particular. Não devemos desprezar, também, o fato de sermos descendentes de um povo que viveu no apogeu do comércio de mercadorias de alto valor de troca. Essa influência ainda se faz sentir entre nós. Enveredamos, de vez em quando, pelos expedientes das 'valorizações' e, freqüentemente, julgamos preferível alcançar um acréscimo de receita por meio de um aumento de preços a consegui-lo em função de um aumento da eficiência da produção. No Brasil, pois, não obstante a evidência do espírito de empreendimen- 
to dos particulares, há a necessidade de uma política governamental com o objetivo de desencorajar a formação de receitas pecuniárias e de incentivar, por vários modos, $\mathrm{o}$ aumento da renda em função do aumento da produção. E a base principal dessa orientação econômica reside num amplo e intenso sistema de política monetária, que, obviamente, envolve a política de investimentos.” Bulhões, Octavio Gouvêa. À margem de um Relatório, p. 7-8

25 Cf. Bulhões, Octavio Gouvêa. Economia e nacionalismo. Revista Brasileira de Economia, Rio de Janeiro, v. 6, n.1, p. 91-118, mar. 1952.

26 Cf. Bulhões, O.G. Depoimento, p. 41. Veja também em Conjuntura Econômica de dezembro de 1990 o último artigo de Bulhões denominado "A liberdade é essencial".

27 Depoimento, p.198.

RESUMO - NESTE artigo procura-se fazer uma síntese da importância de Octavio Gouvêa de Bulhões para a economia brasileira. Considerado um modelo de liberal brasileiro, teve uma atuação marcante como servidor público. Criador do Banco Central e da SUMOC e ministro da Fazenda entre 1964 e 1967, notabilizou-se pela constante preocupação com questões monetárias e financeiras, principalmente com o problema da inflação. Filiado à corrente de pensamento que teve como líder Eugênio Gudin, apresenta uma produção acadêmica que trata das questões de política econômica com o foco central sobre a estabilidade, que considerava fator fundamental para o crescimento econômico. Professor universitário e membro do Instituto Brasileiro de Economia, Octavio Gouvêa de Bulhões, tanto pela vida como pela obra, é uma referência das mais relevantes para o entendimento da economia brasileira.

ABSTRACT - THIS ARTICLE is an attempt to synthesize the important role played by Octavio Gouvêa Bulhões in Brazil's economy. Considered a model Brazilian liberal, Bulhões was a remarkably active civil servant. Founder of Banco Central [Brazil's national bank] and SUMOC [a superintendency for the local currency and credit] and finance minister from 1964 to 1967, he was outstanding for his constant preoccupation about financial and monetary issues, mainly concerning inflation. In tune with the line of thought which had Eugênio Gudin as a leader, Bulhões published academic works dealing with economy policy issues focussing mainly on stability, in his view a fundamental factor for economic growth. A university professor and member of the Instituto Brasileiro de Economia, Octavio Gouvêa Bulhões, both for his life and work, is one of the most important referential names to understand Brazilian economy.

Fausto Saretta é professor do Departamento de Economia da Faculdade de Ciências e Letras da Universidade Estadual Paulista (Unesp). 